\title{
Análisis integral, reconstrucción 3D y propuesta de musealización de la muralla medieval de Mula (Región de Murcia, España)
}

Integral analysis, 3D reconstruction and proposed musealization of the medieval wall of Mula (Region of Murcia, Spain)

\section{Pedro Enrique Collado-Espejo a, Juan Fernández-del-Toro b, Josefina García-León c, Vincenzina La-Spina ${ }^{d}$}

Universidad Politécnica de Cartagena, Cartagena, Spain

a pedroe.collado@ upct.es; ${ }^{\mathrm{b}}$ juanfdt@ gmail.com; ${ }^{\mathrm{c}}$ josefina.leon@ upct.es; ${ }^{\mathrm{d}}$ vincenzina.laspina@upct.es

\begin{abstract}
The city of Mula (Region of Murcia, Spain), still retains important canvases of the medieval wall of the three enclosures (Alcazaba, Albacar and Medina) that shaped the urban layout from the twelfth century (Muslim domain), until the end of the fifteenth century (Christian Reconquest). Currently, the Albacar site is the most complete. On the Islamic Alcazaba was built, in the sixteenth century, the Castle and the wall of the Medina, only a few sections remain. Until now, the medieval wall was a great unknown. The historical landmark of the city has always been the castle. The communication focuses on exposing the exhaustive historical analysis, material, constructive and the state of conservation carried out of the medieval wall of Mula and, especially, of Albacar (the best preserved site). In addition, there has been a virtual volumetric recomposition, in $3 \mathrm{D}$, of the entire Islamic walled complex (walls, towers, entrance doors to the Medina and cistern of Albacar). Also, the musealization of the Albacar site and the recovery of the volume of the cistern has been projected. This work is contributing to the recognition and social awareness of the heritage importance of the Islamic walls of Mula, being a guarantee for its restoration and conservation as a cultural reference of the city.
\end{abstract}

Keywords: Medieval wall, analysis, modelisation 3D, Mula.

\section{Introducción}

Las murallas medievales de Mula (Región de Murcia, España) constituyen el conjunto arquitectónico y patrimonial más antiguo que podemos encontrar en el casco antiguo de la ciudad. Se trata de elementos defensivos que, desde al menos el siglo XII (dominio almohade) hasta el $\mathrm{XV}$, configuraron el trazado urbano de la villa, limitando su expansión. Será con la reconquista cristiana del Reino Nazarí de Granada (finales del siglo XV), cuando la ciudad de Mula comenzará su expansión rebasando el límite de las mu- rallas, aunque el carácter, aún fronterizo de este territorio, hará que durante un tiempo se mantenga la línea de defensa que suponía la muralla medieval para la ciudad.

El casco antiguo de Mula está declarado Bien de Interés Cultural, con categoría de Conjunto Histórico (R.D. 3383/1981) ${ }^{1}$, en el que destaca el Castillo de Los Vélez o de Los Fajardo. Una imponente construcción renacentista que hasta ahora había centrado todas las miradas (y estudios 
científicos), dejando a un lado, casi en el olvido, la muralla medieval.

El trabajo que se expone a continuación viene a cubrir, en parte, la necesidad de un estudio pormenorizado del conjunto fortificado medieval de Mula para su reconocimiento y puesta en valor, pues hasta ahora no había sido objeto de una monografía. No obstante, sí existían algunos estudios y referencias a estas construcciones en la bibliografía local, aunque muy breves. Cabe destacar la obra Una villa del Reino de Murcia en la Edad Moderna (Mula, 1500-1648) (González, 1992) donde, previo al desarrollo de los siglos XVI y XVII, el autor hace un recorrido por la historia de Mula analizando la ocupación musulmana. Entre las aportaciones, destaca un plano aproximado (Fig. 1) del trazado de los recintos amurallados de la villa.

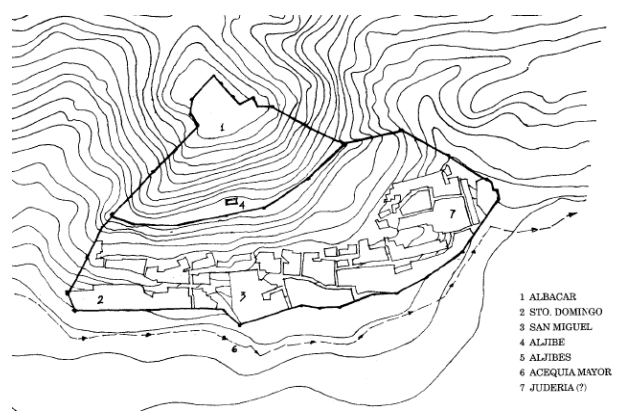

Fig. 1. Plano aproximado del trazado urbano de Mula en época medieval (González, 1992, p. 67).

En este sentido, se ha realizado una amplia investigación histórica, formal y constructiva con el objetivo de documentar y poner en relieve la importancia de la muralla medieval de Mula. Y a partir de este estudio, determinar el trazado y composición (material y constructiva), de la totalidad de los recintos amurallados islámicos, incluso los tramos hoy perdidos, procediendo a su levantamiento gráfico completo (planimétrico y tridimensional). Como veremos más adelante, este levantamiento gráfico permite visualizar y entender cómo sería la ciudad (y sus murallas y puertas de acceso) en época medieval. Además, la propuesta de musealización, incluida en el estudio realizado, pretende contribuir a la puesta en valor de todo el conjunto fortificado.

\section{Mula, una ciudad de frontera}

La ciudad de Mula fue fundada, en su ubicación actual hacia el siglo IX, durante la dominación musulmana. El trazado urbano medieval se desarrolla ladera abajo de un cerro coronado por un conjunto fortificado formado por el castillo renacentista y las murallas islámicas. En sus inicios sería un pequeño asentamiento rural, es decir, una pequeña alquería que, con el tiempo, llegó a convertirse en una ciudad islámica (una medina), y capital de un iqlim o distrito que dominaba un amplio territorio. Su situación estratégica (frontera entre reinos), la fertilidad de sus tierras y sus características defensivas (sobre un monte rocoso, murallas altas, etc.), hicieron que adquiriera una gran importancia. Mula se consideraba un asentamiento casi inexpugnable.

La configuración de la ciudad en época medieval estaba determinada por la irregular orografía del lugar (con escarpadas laderas y grandes crestas rocosas), y el trazado de los gruesos muros que la defendían, los cuales configuraban tres recintos amurallados, que eran independientes y estaban perfectamente identificados: la alcazaba, el albacar y la medina.

El primer recinto, la alcazaba, estaba situado en la coronación de la ciudad, era el más pequeño y contaba con un torreón que sobresalía del resto de la construcción: la Torre del Homenaje. Este recinto daría refugio a una guarnición militar y al gobernante de turno.

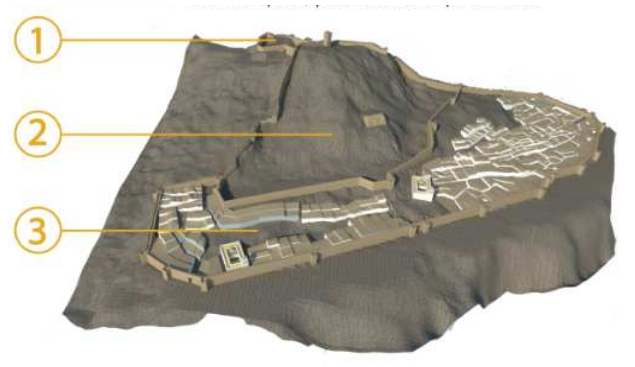

Fig. 2. Recreación gráfica de los recintos amurallados de Mula en época medieval. 1) la Alcazaba; 2) el Albacar; 3) la Medina (J. Fernández-del-Toro).

El segundo recinto, el albacar, se ubica sobre la gran pendiente de la ladera. Se trata de un recinto de transición, de unión entre la parte superior 
(alcazaba) e inferior (medina). La elevada pendiente en la mayor parte de este recinto no permitía levantar construcciones. De hecho, solo existe, además de la muralla, un gran aljibe abovedado conocido actualmente como "la cuerva de los moros". En este caso, el albacar cumplía la función de refugio para el ganado así como de segunda línea de defensa para los habitantes de la ciudad.

El tercer y último recinto era la medina, es decir, la ciudad propiamente dicha. En este recinto se desarrollaba la vida cotidiana de sus habitantes y era donde se ubicaban las viviendas, el zoco, las mezquitas, posiblemente unos hammam o baños, los talleres de artesanía, etc. Las murallas que protegía la medina eran la primera línea de defensa y protección de la población.

A continuación de este recinto, ladera abajo, se desarrollaba una fértil huerta de vertiente cuya producción abastecía a Mula y buena parte de la cercana ciudad de Murcia. Además, esta huerta era fertilizada por otro de los elementos vertebradores de la ciudad de Mula: la Acequia Mayor, que discurría a los pies de la muralla.

\section{Análisis material y constructivo de las mu- rallas medievales de Mula}

El análisis integral realizado a los tramos de muralla islámica de Mula que aún se conservan ha incluido, necesariamente, su estudio material, constructivo y compositivo. Como consecuencia, se puede afirmar que la técnica constructiva empleada en su ejecución fue la llamada tapia calicostrada, sobre cimentación de mampostería de piedra caliza. En algunos tramos de muralla, la cimentación se prolonga por encima de la cota de suelo para aislar la fábrica de tierra de la humedad del terreno. En el caso de las zonas con roca en superficie, el arranque de la tapia apoya directamente en la roca o en pequeñas fábricas escalonadas de mampostería que servían para nivelar los diferentes módulos de tapia que conforman la muralla.

Llama la atención la existencia de mampuestos a modo de remate superior en los mechinales de las agujas de los muros, cuya función era aislar las agujas de madera de la cal vertida sobre ellas, facilitando así la posterior extracción de las mismas al quitar el tapial. Según un estudio cronotipológico realizado y publicado por A. Graciani y M.A. Tabales (2008), estos remates comenzaron a utilizarse con la llegada a la península, en el siglo XII, de los almohades. De ser así, las murallas medievales de Mula, tal como hoy se conocen, debieron de construirse, como pronto, en época almohade.

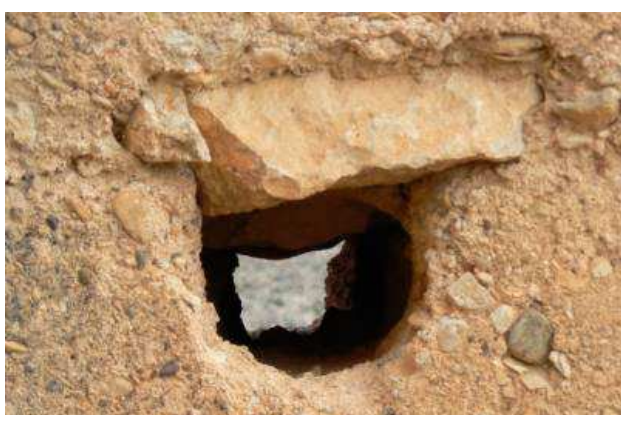

Fig. 3. Mechinal en tapia con remate superior de mampuesto de piedra caliza (J. Fernández-del-Toro).

Es de suponer que anteriormente, en la etapa almorávide (un siglo antes), ya habría murallas aunque los almohades las completarían y afianzarían. Hay que tener presente que muy a menudo, era preciso reparar estas construcciones para mantener una línea defensiva estable y fuerte, por lo que es posible que las tapias conservadas hoy en día, o parte de las mismas, fueran reconstruidas ya en época cristiana (a partir del siglo $\mathrm{XV}$ ), pero existirían desde la época de dominio musulmana.

También se ha realizado un estudio metrológico para poder determinar la unidad constructiva de medida de los módulos de tapia y poder así proponer una recomposición lo más fiel posible a la construcción original. Este estudio ha permitido concluir que en la construcción de los lienzos de muralla que se conservan se utilizó la vara castellana $(0,8359 \mathrm{~m})$ pues es la altura media de los módulos de tapia y las secciones varían de 0,415 $\mathrm{m}$ a $2,08 \mathrm{~m}$. Esto nos induce a pensar que la gran mayoría de los tramos conservados serían consecuencia de una reconstrucción, en época cristiana, de la línea de muralla. Algo muy lógico puesto que tras la reconquista cristiana, la ciudad de $\mathrm{Mu}$ la continuó haciendo uso de su muralla medieval por más de dos siglos. 


\section{Levantamiento gráfico con escáner láser 3D y reconstrucción virtual}

Entre los principales objetivos que se han perseguido con el análisis integral realizado estaba el levantamiento planimétrico completo y de precisión de los tramos de muralla medieval que aún se conservan. La primera fase consistió en la localización e identificación de los lienzos de muralla de los tres recintos en los que se dividía la ciudad. Una labor especialmente complicada por la abrupta orografía del terreno. La toma de datos in situ permitió realizar croquis, mediciones y un preciso reportaje fotográfico (general y de detalle) de los lienzos de muralla y del aljibe del albacar. Una vez localizados todos los elementos a dibujar, se planificó el análisis gráfico con la multiestación Leica Nova MS-50 (escáner láser) del Dpto. de Arquitectura y Tecnología de la Edificación de la Universidad Politécnica de Cartagena.

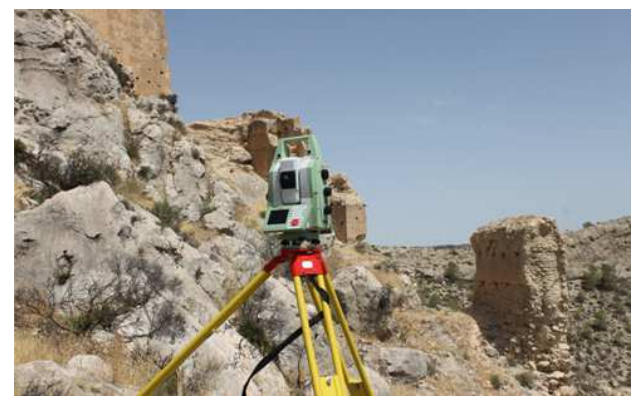

Fig. 4. Multiestación estacionada para escanear un lienzo de la muralla de Mula (J. García-León).

El uso de la multiestación ha sido fundamental para obtener, a través del escaneado de los lienzos islámicos, una gran cantidad de información gráfica de forma rápida, detallada y de gran precisión; identificando materiales y fases constructivas así como reflejando perfectamente las patologías (deterioros, faltas volumétricas...) de estas construcciones.

La metodología de trabajo en estos casos es bien conocida. Una vez definidos los puntos de estacionamiento del aparato y realizados los escaneados, se debe trabajar sobre la nube de puntos generados para obtener los planos de cada uno de los lienzos de muralla. Y para que éstos aporten una mayor información, además de más pre- cisa, clara y descriptiva se insertan ortofotografías (imágenes rectificadas para eliminar el efecto de perspectiva y así facilitar la medición a escala sobre plano), de cada uno de los tramos de muralla. El resultado final de este levantamiento gráfico con el escáner láser 3D es la realización de un modelado en tres dimensiones de los tramos de muralla así como del terreno circundante, con una precisión milimétrica.

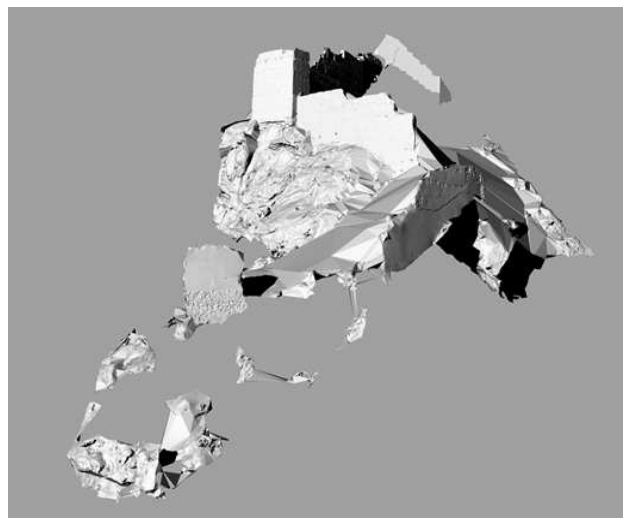

Fig. 5. Levantamiento 3D a partir de la nube de puntos generado por la multiestación (J. Fernández-del-Toro).

Con los planos en CAD y tomando como base la cartografía de la zona (facilitada por los técnicos municipales), se han obtenido las curvas de nivel del terreno y se han colocado en planta, y en su posición exacta, los lienzos de muralla localizados (con la ayuda de imágenes de satélite obtenidas de la web de Cartomur). Finalmente, se ha dibujado en 3D, (con el programa SketchUp), la recomposición de las murallas de los tres recintos islámicos de la ciudad (la alcazaba, el albacar y la medina). Con esta metodología de trabajo gráfico y la información del análisis histórico realizado se ha podido obtener una reconstrucción virtual idealizada de la ciudad en aquella época, facilitando así su recreación e interpretación histórica, social y arquitectónica.

En total, el estudio contempla 19 planos que recogen la ubicación exacta de los lienzos de muralla, plantas, alzados y detalles constructivos de éstos, planos de deterioros (con ubicación, identificación y diferenciación de patologías), y la descripción gráfica detallada (planta, alzados, 
secciones y deterioros detectados) del aljibe islámico, en el recinto del albacar.

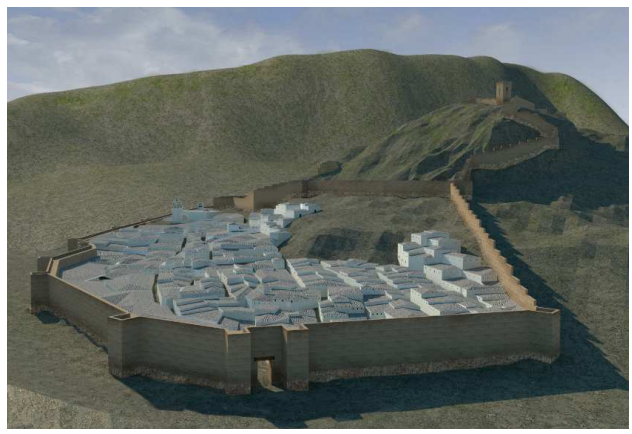

Fig. 6. Reconstrucción virtual idealizada de la ciudad de Mula en época islámica, con los tres recintos amurallados. Destaca la puerta de acceso a la Medina (Collado, et al., 2018, p. 431).

\section{Propuesta de restauración de lienzos de muralla y musealización de "la Senda del Al- bacar"}

Con el levantamiento gráfico de los lienzos de muralla y torres que se conservan se pudo constatar que en el recinto de la alcazaba (que con la construcción del Castillo renacentista quedó muy transformado), apenas quedaban restos islámicos. Del recinto de la medina tampoco se conservaban tramos importantes de muralla pues, durante la expansión de la ciudad (siglos XVI y XVII), muchos lienzos fueron demolidos. Sin embargo, del recinto del albacar (con una extensión de 1,82 hectáreas y cerca de $600 \mathrm{~m}$ de muralla en origen), aún quedaban en pié 16 lienzos, 7 torres y el aljibe, aunque la gran mayoría en un estado de conservación bastante precario. Por tanto, el estudio integral que se estaba realizando debía contemplar también una propuesta detallada de restauración y conservación de, al menos, los lienzos de muralla del recinto del albacar y, para su correcta conservación y puesta en valor, la musealización de todo este recinto que incluye, necesariamente, el acondicionamiento del entorno natural y trama urbana.

Además, al tratarse de elementos protegidos (la muralla tiene categoría de monumento), los criterios de intervención deben estar basados en el conocimiento y respeto absoluto a los valores históricos, arquitectónicos, sociales y culturales que atesoran estos muros, evitándose la reconstrucción del bien y potenciando su consolidación y conservación (en cumplimiento de la Ley 4/2007 de Patrimonio Cultural de la Región de Murcia).

Por tanto, la propuesta de intervención comienza con la consolidación, conservación y restauración de los tramos de muralla y torres. A grandes rasgos, se proyecta la limpieza de paramentos y la consolidación y conservación de las estructuras (lienzos de muralla y torres) existentes. Se proyecta la reintegración de material en zonas con pérdida de sección y la recomposición de coronaciones de muralla y/o torres deterioradas). Esta intervención se debe realizar con la técnica constructiva de la tapia calicostrada y tomando la vara castellana como unidad de medida, por ser la técnica original del monumento. Además, se deben diferenciar las partes nuevas de las originales, de manera sutil, para no distorsionar la imagen general de los tramos de muralla actuales. De esta manera, se reduce el riesgo de desplomes y/o derrumbes y se hace legible el trazado de la muralla.

Para la recuperación volumétrica del aljibe (en el recinto del albacar), el criterio de intervención propuesto es ligeramente distinto al de los lienzos de muralla y torres. Como la propuesta de intervención incluye la puesta en valor de todo el recinto monumental del albacar a través de su musealización, se propone convertir el aljibe en un espacio acondicionado para albergar el que llamaríamos "Centro de interpretación de la $\mathrm{Mu}$ ralla Islámica de Mula".

Por tanto, además de la limpieza completa del interior del aljibe y de su entorno inmediato (con la correspondiente supervisión arqueológica), y la consolidación estructural de los muros, se proyecta la recomposición volumétrica completa de este elemento, incluida la bóveda de ladrillo. Para diferenciar los materiales originales de los nuevos, la recomposición volumétrica de la bóveda del aljibe se ha proyectado con una ligera estructura metálica revestida interior y exteriormente con madera. De esta manera, el añadido queda perfectamente diferenciado del original facilitando la lectura constructiva de la actuación, así como su posible desmontaje futuro (si 
fuera necesario). La solución técnica para la estructura metálica consiste en unos mínimos apoyos en los muros de tapia, logrando así que la intervención sea reversible.

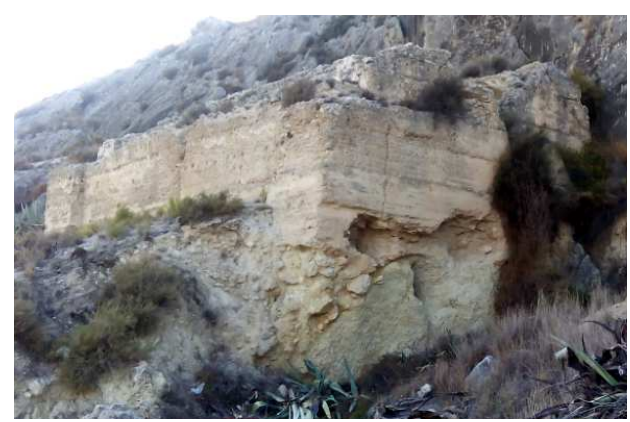

Fig. 7. Vista general del estado actual del aljibe, en el albacar (J. Fernández-del-Toro).

Por otra parte, la propuesta de actuación en los 16 tramos de muralla y 7 torreones del recinto del albacar tiene muy presente la idea de que sólo los monumentos que tienen un uso son conservados y mantenidos correctamente. Evidentemente, el uso futuro de estos elementos patrimoniales tiene que ser absolutamente respetuoso y compatible con todos los valores que atesoran. Por tanto, se ha proyectado la puesta en valor del recinto del albacar, dándole un uso cultural y turístico a través de su musealización, lo que conlleva el tratamiento de las sendas y calles donde encontramos lienzos de muralla, y el correcto acondicionamiento de su entorno urbano, natural y paisajístico.

Como se ha comentado, el aljibe albergaría un centro de interpretación de la ciudad en época medieval. A pesar de sus reducidas dimensiones, se pretende dar relevancia patrimonial, social y cultural a este elemento arquitectónico pues, si las murallas eran importantes para proteger la ciudad, el aljibe era fundamental para la vida de los pobladores. Es por ello que el depósito pasaría a tener un gran protagonismo en este nuevo entorno cultural. En su interior se colocarían diferentes paneles informativos y divulgativos (que se han diseñado como recurso didáctico y formativo básico), para su puesta en valor y musealización. Estos paneles sirven para informar, documentar y mostrar, a los vecinos de Mula y a los posibles visitantes, la forma en que se construía en época islámica (la técnica del muro de tapia calicostrada) así como de las condiciones históricas y compositivas del albacar y su relación con el entorno urbano y paisajístico. De esta manera se facilita la correcta lectura e interpretación de todo el conjunto patrimonial.

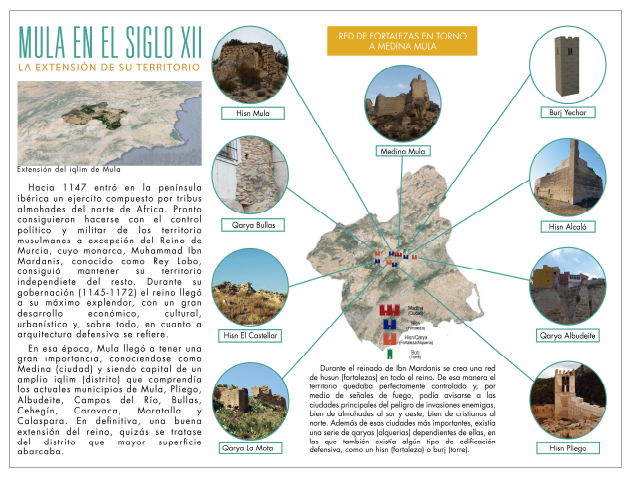

Fig. 8. Ejemplo de uno de los paneles expositivos diseñados para la musealización de la Senda del Albacar (J. Fernández-del-Toro).

El recinto del albacar es atravesado por una senda o camino en su parte inferior conocida como "Senda del Albacar" que permite recorrer este entorno histórico, arquitectónico y natural, además de disfrutar del paisaje y de las vistas de la ciudad.

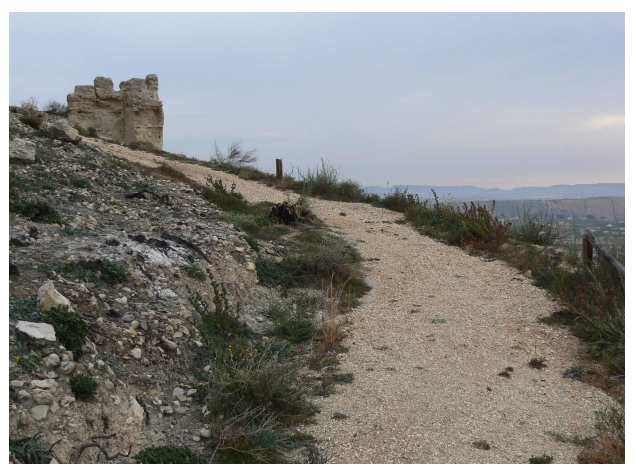

Fig. 9. Vista actual de la senda o camino del albacar. Al fondo aparece un lienzo de muralla del recinto del albacar (J. Fernández-del-Toro).

Por tanto, resulta imprescindible la adecuación de esta senda, haciéndola accesible y segura para ser transitada por cualquier persona. En torno a esta senda, se plantea el ajardinado de las zonas 
que no presenten restos arqueológicos (tras las pertinentes excavaciones). Para ello, es preciso desmontar una serie de construcciones existentes en la entrada del albacar, a poniente, y que se encuentran en claro estado de ruina y que se consideran sin valor patrimonial.

Con todas estas actuaciones creemos que se conseguiría la recuperación y revitalización de este espacio patrimonial para la ciudad de Mula, (actualmente muy deteriorado), y se potenciaría la ciudad como referente histórico-cultural de ciudad que en época medieval fue frontera entre dos reinos y dos culturas, la nazarí (islámica) y la cristiana.

\section{Conclusiones}

Las murallas medievales de Mula jugaron un papel fundamental para la ciudad desde su construcción, en época altomedieval, hasta su derribo parcial (en el caso del recinto de la medina, tras la rendición del reino nazarí de Granada, en 1492). No solo protegieron a la población de los constantes ataques enemigos, también fueron un elemento vertebrador del urbanismo de la ciudad, pues establecían sus límites a los cuatro puntos cardinales. Aún hoy podemos disfrutar en sus calles de elevadas pendientes y laberínticos trazados, típicos de una villa medieval.

La ciudad se estructuraba en tres recintos: la alcazaba, el albacar y la medina. Por desgracia, actualmente no es posible contemplar los altos muros de la primera línea de defensa (la muralla de la medina), pues fueron derribados (a partir del siglo XVI), con la expansión de la ciudad. Sí se conservan algunos lienzos de la muralla islámica de la alcazaba, aunque con la construcción del Castillo de Los Vélez (siglo XVI, renacentista), se transformó todo el recinto. Por contra, el recinto intermedio, el del albacar, sí conserva bastantes lienzos de muralla y torres. En concreto, se han identificado y estudiado 16 lienzos de muralla y 7 torres. Los tramos de muralla de estos recintos (alcazaba y albacar), requieren de una importante restauración que permita su conservación y una correcta lectura histórica, constructiva, social y cultural. Por ello, se ha realizado un análisis integral y una propuesta de restauración y musealización (con recomposición vir- tual 3D incluida), con el fin de contribuir al reconocimiento y difusión de esta parte tan importante de la historia social y cultural de la localidad.

Se ha analizado y documentado in situ el recorrido original de la muralla en sus tres recintos. $\mathrm{Y}$ se ha estudiado los materiales, sistemas constructivos y estado de conservación de los lienzos y torres que aún se conservan. Con la documentación gráfica recogida, tanto fotográfica como planimétrica, y el trabajo de campo realizado, la muralla ha quedado completamente documentada. Un trabajo de especial importancia atendiendo al mal estado de conservación en que se encuentran. Así, ante cualquier desastre natural, como un terremoto (Mula se encuentra en una zona de elevada sismicidad), que pudiera desplomar alguno de los lienzos o torres, contaríamos con una precisa documentación gráfica para su recuperación.

En base al análisis integral y levantamiento gráfico, se ha propuesto la restauración de los tramos de muralla y el aljibe del albacar, así como su puesta en valor y difusión a través de la musealización del conjunto, que incluye el adecuado tratamiento del entorno natural y paisajístico. La reconstrucción virtual 3D de la ciudad islámica, con sus tres recintos, sus murallas, torres y puertas de acceso, permiten mostrar e interpretar histórica, arquitectónica, social y culturalmente un periodo muy importante de la ciudad de $\mathrm{Mu}$ la. Los paneles informativos y divulgativos que se han diseñado así como el acondicionamiento del aljibe y de la senda del albacar deben acercar y hacer disfrutar a la población y visitantes de todo este entorno patrimonial.

En definitiva, se considera que la investigación realizada y los resultados que se han obtenido deben servir de punto de partida de la necesaria recuperación integral, conservación y puesta en valor de la muralla medieval de Mula, y deben contribuir a la definitiva revitalización de esta zona del Conjunto Histórico de la ciudad.

\section{Notes}

${ }^{1}$ Real Decreto 3383/1981, de 27 de noviembre, por el que se declara Conjunto HistóricoArtístico la ciudad de Mula (Murcia). BOE n²1, 
de 25 de enero de 1982. (Con la entrada en vigor de la Ley 16/1985 pasa a ser Bien de Interés Cultural con categoría de Conjunto Histórico).

\section{Bibliography}

Collado, P.E.; García J.; La Spina, V.; Fernández, J. (2018). "The islamic wall of Mula (Spain): 3D reconstruction, restoration and musealization", in Vernacular and Earthen Architecture: Conservation and Sustaunability, Taylos \& Francis Group, London, pp. 429-434.

Eiroa, J.A. (2016). "El legado de Ibn Mardanis", Debates de Arqueología Medieval, 6, pp. 247-258.

Fernández, J. (2018). "Las murallas medievales de Mula (Murcia). Análisis integral y propuesta de restauración de la muralla del albacar", in XXIV Jornadas de Patrimonio Cultural de la Región de Murcia, Tres Fronteras Ediciones, Murcia, pp. 51-57.

González, J. (1992). Una villa del Reino de Murcia en la Edad Moderna (Mula, 1500-1648), Real Academia Alfonso $\mathrm{X}$ El Sabio, Murcia.

González, R.; Fernández, F. (2010). "Mula, el final de una ciudad de la cora Tudmir”, PYRENAE Revista de Prehistòria i Antiguitat de la Mediterrània Occidental, 41, 2, pp. 81-119.

Graciani, A.; Tabales, M.A. (2008). "El tapial en el área sevillana. Avance cronotipolígico estructural”, Revista Arqueología de la Arquitectura, 5, pp. 135-158.

Martínez, A. (2013). Lorca Almohade: Ciudad y territorio, Universidad de Murcia Ed., Murcia.

Mileto, C.; Vegas, F. (2014). La restauración de la tapia en la Península Ibérica. Criterios, técnicas, resultados y perspectivas, TC Cuadernos, Valencia.

Molina, E. (1995). Aproximación al estudio de Mula islámica, Ayutamiento de Mula, Comunidad de Regantes del Pantano de la Cierva, Mula.

Navarro. J.; Jiménez, P. (2012). "La arquitetura de Ibn Mardanish; revisión y nuevas aportaciones”, in Aljafería y el arte del Islam occidental en el siglo XI, CSIC, Zaragoza, pp. 291-350.

Zapata, J.A. (2015). El Castillo de Mula (Murcia), Ayuntamiento de Mula, Mula. 